\title{
Cultural and Reproductive Variability of Corynespora cassiicola from Different Host Plants
}

\author{
M.M.K. Peiris ${ }^{1}$, T.H.P.S. Fernando ${ }^{2 *}$, D. Gunawardana ${ }^{1}$, E.A.D.N. Nishantha ${ }^{2}$, \\ G.P.W.P.P. Seneviratne ${ }^{2}$ \\ ${ }^{1}$ Department of Botany, University of Sri Jayawardenepura, Sri Lanka \\ ${ }^{2}$ Rubber Research Institute, Dartonfield, Agalawatte, Sri Lanka \\ *thpsfernando@yahoo.com
}

\begin{abstract}
Natural rubber industry plays an important role in the economy of Sri Lanka. Therefore, improvement of productivity levels has become important. Corynespora leaf fall disease (CLFD) is the most destructive disease of rubber caused by Corynespora cassiicola. In Sri Lanka two epidemics occurred in 1986 and 1995. C. cassiicola has a wide host range including vegetables, ornamentals, weeds, yams, medicinal and other cash crops. Hence, there is a high risk of cross infection possibilities. The objective of this study was to examine the diversity of the pathogen isolates from several host plants; rubber-RRISL202 (A), RRISL 110 (B), RRISL201 (C), Eggplant (D), Papaya (E), Tomato (F). Diseased leaf samples were collected and isolated on potato dextrose agar (PDA). Single spore isolates were obtained and the cultural variations were studied. Except flat textured D and E, all the other isolates showed puffy growth. Colony appearance varied from olivaceous green colour to different shades of grey. Except A, B and C all the other isolates showed concentric rings on lower surface. Except A and B, the other isolates showed uneven margins. In microscopic view, all rubber isolates showed thread like hyphae with a width of (3.20-3.58) $\mu \mathrm{m}$. However, in the isolates of alternative hosts, hyphae were wider $(6.00-7.80 \mu \mathrm{m})$. Generally mycelia were branched and septate with conidiophores at the tips of hyphae. Isolates A, B and C were fast growers, $\mathrm{D}$ and $\mathrm{E}$ were moderate while $\mathrm{F}$ was slow. In reproductive studies, generally conidia of $C$. cassiicola were segmented and showed characteristic hilum at the pointed tips. There was no significant variation in the dimensions of spores among the isolates. The conidial length varied from $(15-275 \mu \mathrm{m})$ and width varied from $(3.75-12.50 \mu \mathrm{m})$. Straight, curved, cylindrical and obclavate shapes were observed. Mostly slender, straight conidia were observed in rubber isolates. Rubber isolates were poor sporulators compared to the alternative host isolates. Present study revealed that there is a significant variation in the morphology and reproductive characteristics among the selected $C$. cassiicola isolates. Further investigations will be carried out to examine the genetic and pathogenicity variations among the isolates.
\end{abstract}

Keywords: Corynespora cassiicola, Alternative hosts, Morphology and reproductive Characteristics 